\title{
Proliferation Marker (Ki67) in Sub-Categorization of Neuroendocrine Tumours of the Lung
}

\author{
Rashi GARG ${ }^{1}$ iD , Amanjit BAL ${ }^{1}$ iD, Ashim DAS ${ }^{1}$ iD, Navneet SingH² iD, Harkant SiNGH ${ }^{\text {iD }}$ \\ Departments of ${ }^{1}$ Histopathology, ${ }^{2}$ Pulmonary Medicine, and ${ }^{3}$ Cardiovascular and Thoracic Surgery, \\ Post Graduate Institute of Medical Education \& Research (PGIMER), CHANDIGARH, INDIA
}

\begin{abstract}
Objective: The 2015 WHO classification classifies neuroendocrine tumours (NET) of the lung into typical carcinoid, atypical carcinoid, large cell neuroendocrine carcinoma and small cell carcinoma based on morphology alone. Mitosis is the major parameter for this classification, and thus several studies have focused on the role of Ki67 in these tumours but without conclusive results. The aim of the study was to categorize neuroendocrine tumours of the lung based on morphology and to assess the utility of Ki67 in diagnosis.
\end{abstract}

Material and Method: The study included 42 cases (23 biopsies and 19 lobectomy specimens) of neuroendocrine tumours (excluding small cell carcinoma). Haematoxylin \& eosin stained sections, immunohistochemistry for neuroendocrine markers and Ki67 were studied.

Results: Based on WHO criteria, cases were classified as typical carcinoids (83.3\%), atypical carcinoids (12\%) and large cell neuroendocrine carcinomas (4.7\%). The Ki67 index ranged between 1\%-10\% (mean 2.6\%), 10\%-30\% (mean 19\%), 35\%-50\% (mean 42.5\%) in typical carcinoid, atypical carcinoid and large cell neuroendocrine carcinoma respectively. Using the ROC curve, the cut off value of Ki67 for typical and atypical carcinoids was 7.5\% (P value $<0.001$ ), and for atypical carcinoid/large cell neuroendocrine carcinoma was $32.5 \%$ ( $\mathrm{P}$ value $=0.051)$. On comparing the size and infiltration pattern (both local and lymphovascular invasion) of tumours in resected specimens, there was no association with the proliferation index $(\mathrm{P}$ value $>0.05)$.

Conclusion: Morphological features are the gold standard for subtyping of neuroendocrine tumours. Ki-67 is a potentially meaningful marker for sub-categorization of lung NETs, especially in small biopsies. However, the size and infiltrative pattern of the tumours are independent of the proliferation index.

Key Words: Ki67, Lung, Neuroendocrine tumours

\section{INTRODUCTION}

The lung is a common site of carcinoid tumours and accounts for $30 \%$ of well differentiated neuroendocrine tumours (NETs) in the body (1). The 2015 World Health Organization (WHO) classification recognizes 4 major types of neuroendocrine tumours (NETs) of the lung: typical carcinoid (TC), atypical carcinoid (AC), large cell neuroendocrine carcinoma (LCNEC) and small cell carcinoma (SCC). Excluding SCC, the remaining NETs constitute $5 \%$ of lung tumours (2). Currently, WHO classifies these tumours based on the morphologic features of which mitoses and necrosis are of paramount importance. Several studies have tried to evaluate the role of Ki67 similar to other organ sites such as the gastrointestinal tract and pancreas in diagnosing these tumours but without conclusive results. Since these subtypes of lung NETs have markedly different prognostic implications and treatment regimens, the importance of accurate pathologic diagnosis is underscored. The aim of this study was to assess the

(Turk Patoloji Derg 2019, 35:15-21)

Received : 10.02.2018 Accepted : 25.06.2018 utility of proliferation marker Ki67 in sub-categorization of these tumours (excluding SCC).

\section{MATERIAL and METHODS}

Forty two cases (23 biopsies and 19 lobectomy specimens) of NETs of the lung excluding SCC of lung were analyzed retrospectively from Jan 1999 to Aug 2014. Sections prepared from paraffin blocks were stained with hematoxylin and eosin and the morphological features were studied.

\section{Morphology}

Cases were classified based on morphological criteria used by 2015 WHO classification. Tumours with carcinoid morphology, $<2$ mitoses per $2 \mathrm{~mm}^{2}$ and lacking necrosis were classified as TC, those with carcinoid morphology and 2-10 mitoses per $2 \mathrm{~mm}^{2}$ or necrosis (often punctate) were categorized as AC. The tumours with neuroendocrine morphology, positive immunohistochemical staining for one or more NE markers (other than neuron-specific enolase), high mitotic rate: $\geq 11$ per $2 \mathrm{~mm}^{2}$, necrosis (often

Correspondence: Amanjit BAL

Departments of Histopathology, Post Graduate Institute of Medical Education \& Research (PGIMER), CHANDIGARH, INDIA

E-mail: docaman5@hotmail.com Phone: +7087008134 
Table I: Comparison of Age and M:F ratio in different tumour types.

\begin{tabular}{cccccc}
\hline Tumour type & \multicolumn{3}{c}{ Age } & M:F \\
\hline TC & Range & Mean & Median & Standard deviation & $1: 1.2$ \\
\hline AC & $18-72$ & 37.56 & 38 & 15.06 & $1.5: 1$ \\
\hline LCNEC & $21-65$ & 34.4 & 31 & 20.46 & Both males \\
\hline
\end{tabular}

TC: Typical carcinoid; AC: Atypical carcinoid, LCNEC: Large cell neuroendocrine carcinoma, M:Male, F:Female.

Table II: Values of Ki67 in different tumour types.

\begin{tabular}{lcc}
\hline Tumour type & Range & Mean \\
\hline TC & $1-10$ & 2.6 \\
\hline AC & $10-30$ & 19 \\
\hline LCNEC & $35-50$ & 42.5 \\
\hline
\end{tabular}

TC: Typical carcinoid; AC: Atypical carcinoid, LCNEC: Large cell neuroendocrine carcinoma.

large zones) and cytologic features of a non-small-cell lung carcinoma i.e. large-cell size, low nuclear to cytoplasmic ratio, vesicular or fine chromatin, and/or frequent nucleoli were classified as LCNEC.

\section{Immunohistochemistry}

Neuroendocrine Markers: Immunohistochemistry for one of the neuroendocrine markers; chromogranin, synaptophysin and CD56 was done in all cases.

Proliferation Index: The Ki-67 proliferative index was determined in all cases on formalin-fixed paraffinembedded tissue sections using a mouse anti-Ki-67 monoclonal antibody (1:50; clone MIB-1; Dako). Five hot spots i.e. areas of highest proliferation were counted. A total of 1000 cells in each spot were counted and results were expressed in percentage.

\section{Statistical Analysis}

Microsoft Excel was used for all the calculations. The Ki67 distribution among WHO 2015 categories (TC, AC, LCNEC) was investigated using non parametric test: the Kruskal-Wallis equality of population rank test and Mann-Whitney tests. Receiver Operating Characteristic (ROC) curve was used to decide the cutoff value of Ki67 in distinguishing these tumours with maximum sensitivities and specificities.

\section{RESULTS}

\section{Clinico-Pathological Parameters}

The patients were of an age group ranging from 18 to 72 years. Mean age was 37.56 (median 38) for TC, 34.40 (median 31) for AC and 56 years for LCNEC. Patients with LCNEC presented in the $5^{\text {th }}$ and $6^{\text {th }}$ decades whereas patients with $\mathrm{AC}$ and TC presented from the $2^{\text {nd }}$ to $7^{\text {th }}$ decades
(Table I). The male-female ratio was 1.15:1 (Table I). All the cases were showing neuroendocrine architecture-organoid nests, trabeculae and rosettes and all were positive for one or more neuroendocrine markers (CD56, synaptophysin and Chromogranin). Based upon morphology, of the 42 cases $35(83.3 \%)$ were TC (Figure 1A-D), 5 (12\%) were AC (Figure $2 \mathrm{~A}$ ) and $2(4.7 \%)$ cases were LCNEC (Figure 3AC).

\section{Proliferation Index}

Ki67 index ranged between 1\%-10\% (mean 2.6\%), 10\%$30 \%$ (mean 19\%), and 35\%-50\% (mean $42.5 \%$ ) in TC, AC and LCNEC respectively (Figure 1D, 2B, 3D respectively) (Table II). The Kruskal-Wallis equality of population rank test showed a statistically significant difference between the three categories of tumours with a $\mathrm{P}$ value $<0.001$. Using the Mann-Whitney test, a significant difference was found for pairwise comparison between TC and AC with a $\mathrm{P}$ value $<0.001$. However, the results were not found to be significant between AC and LCNEC with a $\mathrm{P}$ value 0.051. Using the ROC curve, the cut off value of Ki67 for typical/atypical carcinoids was $7.5 \%$ with sensitivity and specificity of $91.4 \%$ and $100 \%$ (area under curve is 0.9685 ) (Figure $4 \mathrm{~A}, \mathrm{~B}$ ), whereas for atypical carcinoid/large cell neuroendocrine carcinoma, the cut off value was 32.5\% with sensitivity and specificity of $100 \%$ (Figure 4C,D) (area under curve is 1). Overall the Ki67 cutoffs discriminated with optimal discrimination power between 3 classes.

\section{Resection Specimens}

The pneumonectomy/lobectomy specimens were available in 19 cases. Of these, three cases were AC and remaining 16 cases were TC. The size of the tumours ranged from 1 to $9 \mathrm{~cm}$ (in the largest dimension). On gross examination, all cases were well circumscribed except four cases (Figure 5). On microscopic examination, 9 cases had infiltrative margins, of which two showed lymphovascular involvement; both were TCs. Of the three ACs, two showed infiltrative margins. Lymph nodes (hilar/peribronchial/subcarinal) were available in 6 cases which were free of tumour. On comparing the size and infiltration pattern (both local and lymphovascular invasion), using the T-test and Pearson Correlation, there was no association with the proliferation index ( $\mathrm{P}$ value $>0.05$ ) as well as tumour type. 

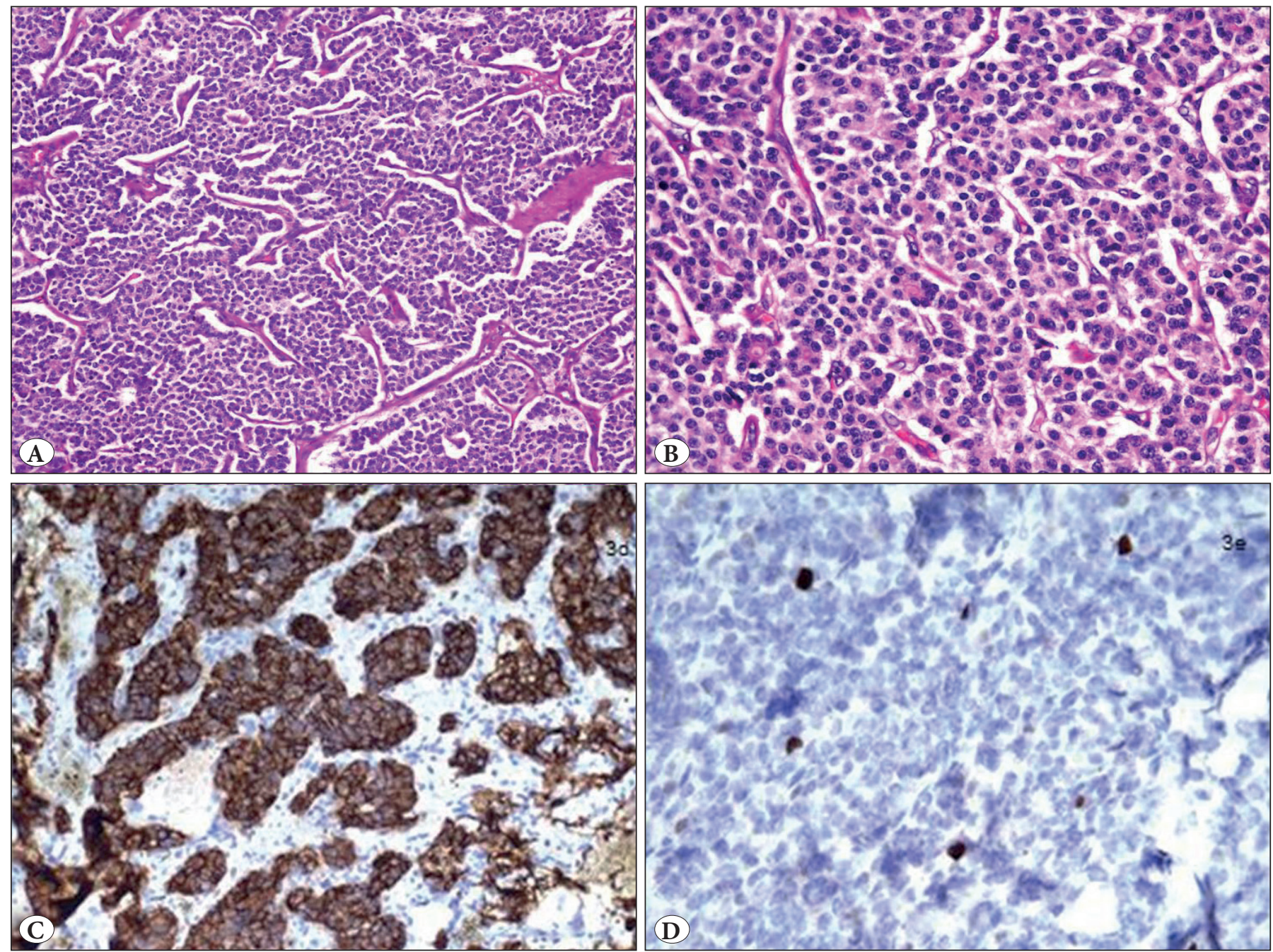

Figure 1: Typical Carcinoid. Photomicrographs showing A-B) Organoid pattern of arrangement (H\&E; x100 and x200). C) Cytoplasmic positivity with chromogranin (IHC; x200). D) Ki67 staining nuclei of $<1 \%$ of cells (IHC; x400).
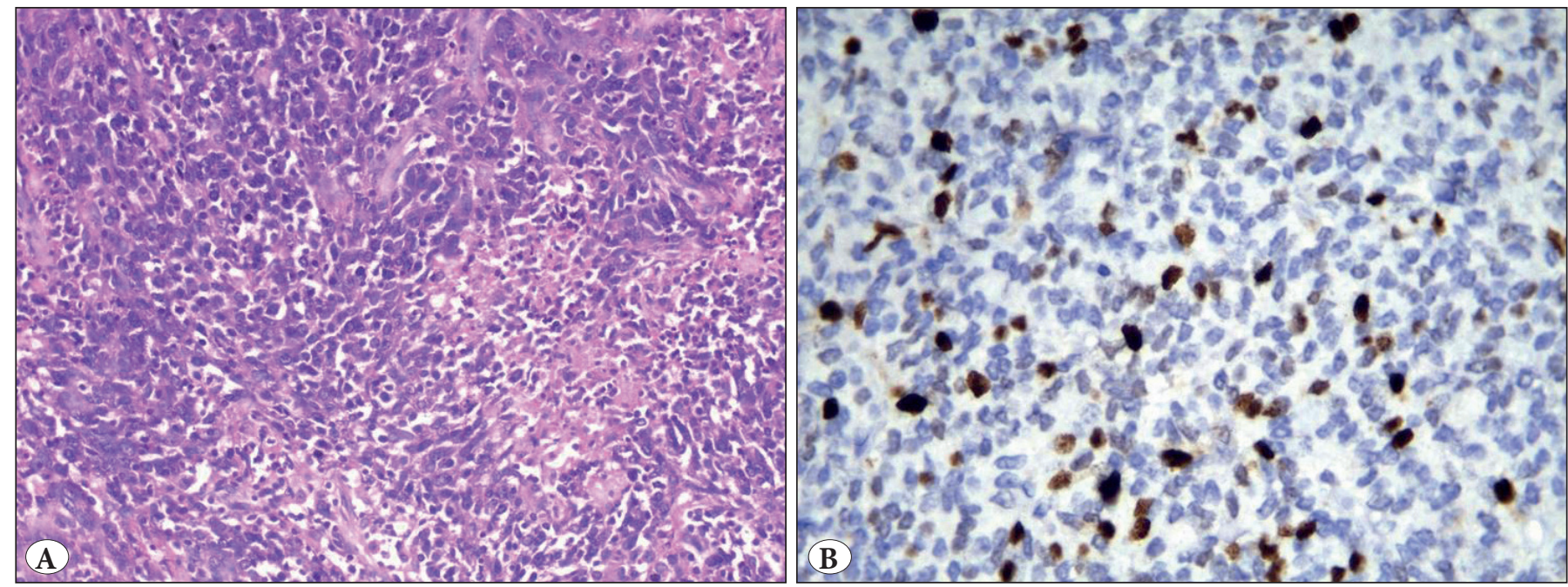

Figure 2: Atypical Carcinoid. A) Photomicrographs showing focal areas of necrosis. (H\&E; x10X). B) Ki67 shows nuclear staining in 20\% of the tumour cells (IHC; x40). 


\section{DISCUSSION}

NETs of the lung include four different histologic subtypes as defined by WHO; Typical carcinoid (TC-1-2\%), atypical carcinoid (AC-0.1-0.2\%), large cell neuroendocrine carcinoma (LCNEC-3\%) and small cell carcinoma (SCC$15-20 \%)(2,3)$. TCs are associated with a fairly benign behavior and are classified as low grade NET/Carcinoma (Grade 1), ACs are classified as intermediate grade tumour (Grade 2), whereas LCNEC and SCC are grouped together under high grade NET/Carcinoma (Grade 3) (2). Of the high grade tumours, the SCCs have distinct nuclear morphology posing less diagnostic problems, and thus were excluded from the study. The main concern lies in distinguishing low and intermediate grade tumours (TC/AC).

The WHO 2015 classifies these tumours based on morphological features only, which includes carcinoid morphology, mitosis and/or necrosis. All these tumours have positive immunohistochemical staining for one or more NE markers. The difficulties in classifying these tumours arise in rare tumours that show mitotic activity just slightly or focally exceeding $2 / 2 \mathrm{~mm}^{2}$ or $10 / 2 \mathrm{~mm}^{2}$ which otherwise would qualify as AC or LCNEC respectively (4). Also, in small biopsies with extensive crush artifact it is difficult to count mitotic figures and when the amount of tumour tissue is limited $(5,6)$. To overcome these difficulties, an effective grading system for digestive NETs was recently introduced by the European Neuroendocrine Tumour Society and endorsed by the WHO and the American Joint Cancer Committee (7). This system largely relies on the assessment of the proliferative marker Ki67 which proved accurate and predictive (8). Different studies have assessed the role of proliferation marker Ki67 in lung neuroendocrine tumours but the results are not conclusive $(9,10)$.
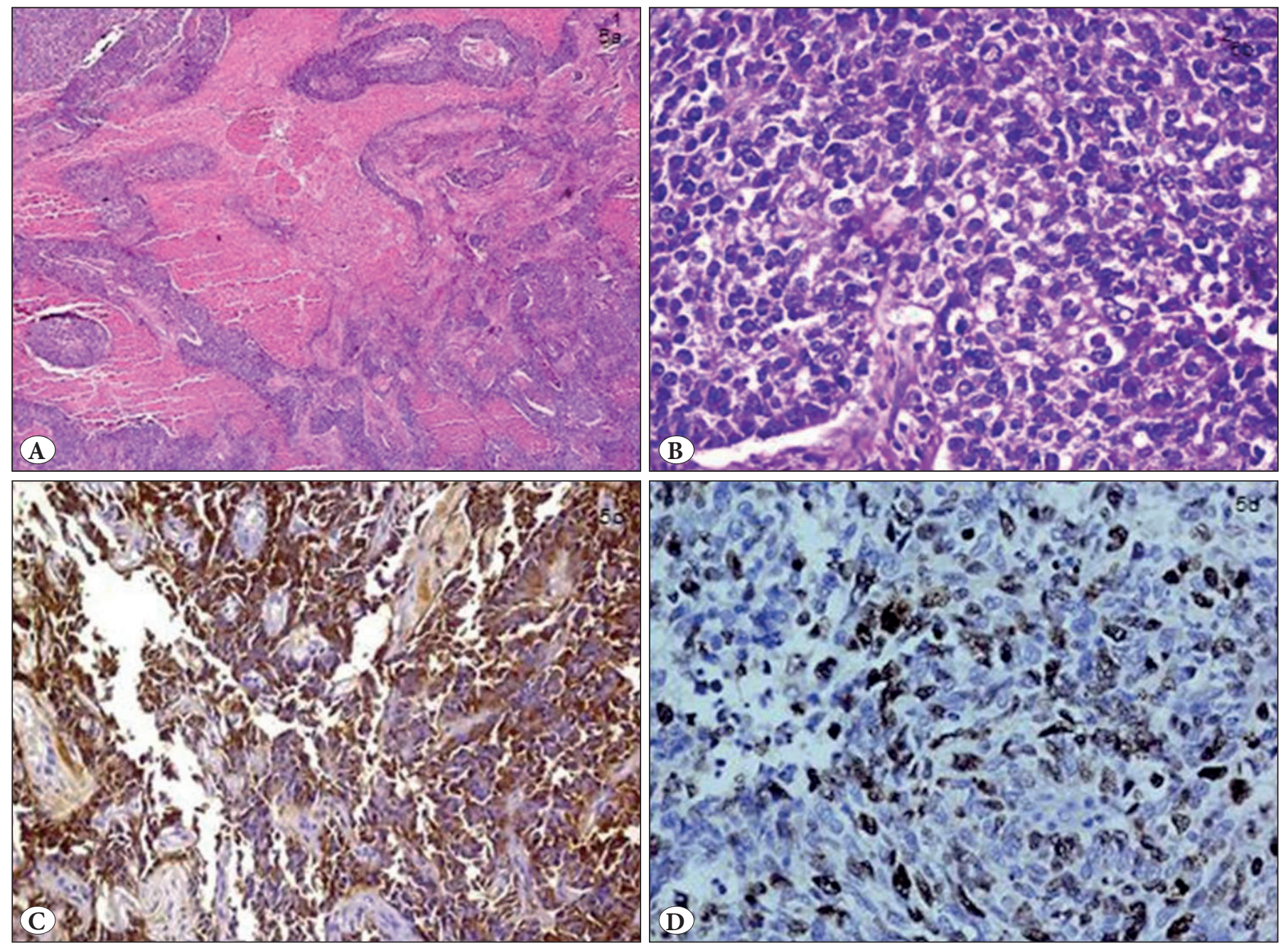

Figure 3: LCNEC. Photomicrographs showing A) extensive areas of necrosis with organoid pattern (H\&E; x10). B) Large cell size, vesicular nucleus, prominent nucleolus and frequent mitosis (H\&E; x40). C) Cytoplasmic positivity with synaptophysin (IHC; 20 ). D) Ki67 staining nuclei of $35 \%$ of cells (IHC; x40). 


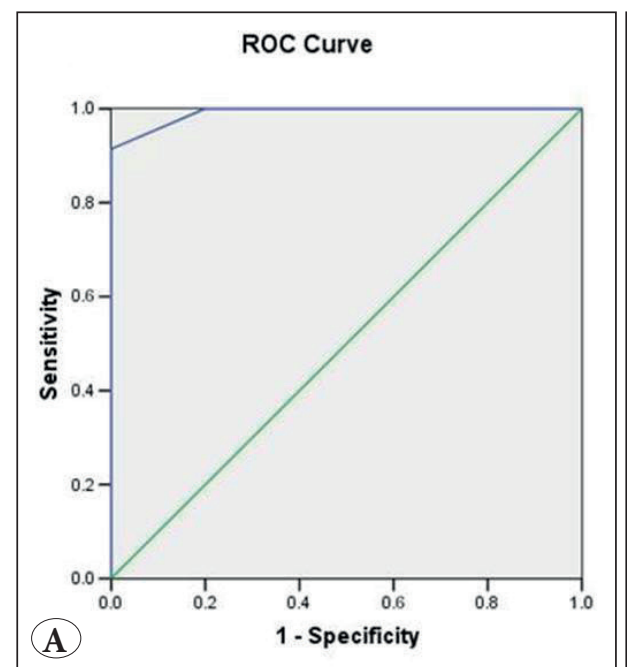

\begin{tabular}{|c|c|c|}
\hline \multicolumn{3}{|c|}{$\begin{array}{l}\text { Coordinates of the Curve } \\
\text { Test Result Vaniable(s): KI67PERCENT }\end{array}$} \\
\hline Positive if Less Than or Equal To(a) & Sensitivity & 1-Specificity \\
\hline .0000 & .000 & .000 \\
\hline 1.5000 & .486 & .000 \\
\hline 3.5000 & |771 & .000 \\
\hline 7.5000 & .914 & .000 \\
\hline 12.5000 & 1.000 & .200 \\
\hline 17.5000 & 1.000 & .400 \\
\hline 25.0000 & 1.000 & .800 \\
\hline 31.0000 & 1.000 & 1.000 \\
\hline \multicolumn{3}{|c|}{$\begin{array}{l}\text { The test result variable(s): KI67PERCENT has at least one tie between thepositive actual state group and thenegative } \\
\text { actual state group. }\end{array}$} \\
\hline \multicolumn{3}{|c|}{$\begin{array}{l}\text { a. The smallest cutoff valueis the minimumobservedtest valueminus } 1 \text {, and thelargest cutoff valueis the maximum } \\
\text { observed test valueplus } 1 \text {. All the other cutoff values are the averages of two consecutive ordered observed test values. }\end{array}$} \\
\hline
\end{tabular}

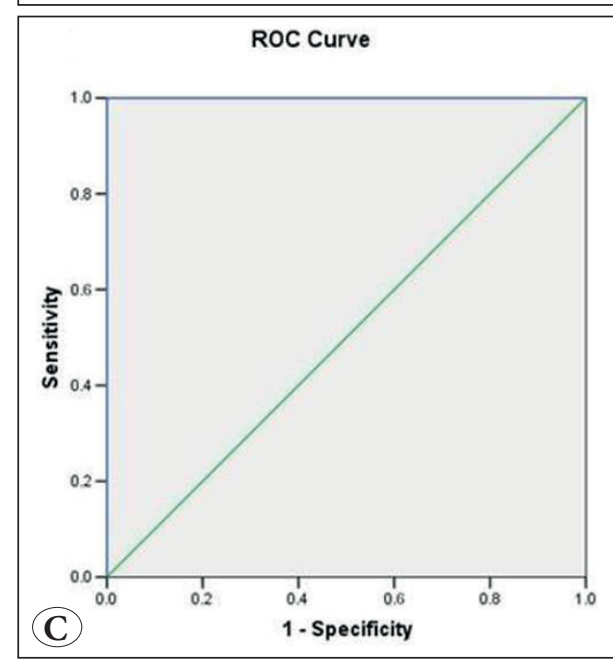

\begin{tabular}{|c|c|c|}
\hline \multicolumn{3}{|c|}{$\begin{array}{l}\text { Coordinates of the Curve } \\
\text { Test Result Variable(s): KI67PERCENT }\end{array}$} \\
\hline Positive if Less Than or Equal To(a) & Sensitivity & 1-Specificity \\
\hline 9.0000 & .000 & .000 \\
\hline 12.5000 & .200 & .000 \\
\hline 17.5000 & .400 & .000 \\
\hline 25.0000 & .800 & .000 \\
\hline 32.5000 & 1.000 & .000 \\
\hline 42.5000 & 1.000 & .500 \\
\hline 51.0000 & 1.000 & 1.000 \\
\hline \multicolumn{3}{|c|}{$\begin{array}{l}\text { a. The smallest cutoff valueis the minimumobservedtest valueminus } 1 \text {, and thelargest cutoff valueis the maximum } \\
\text { observed test valueplus } 1 \text {. All the other cutoff values are the averages of two consecutive ordered observed test values. }\end{array}$} \\
\hline & & \\
\hline
\end{tabular}

Figure 4: A-B) ROC-Ki67 cutoff values with different sensitivities and specificities for TC/AC. C-D) ROC-Ki67 cutoff values with different sensitivities and specificities for AC/LCNEC.
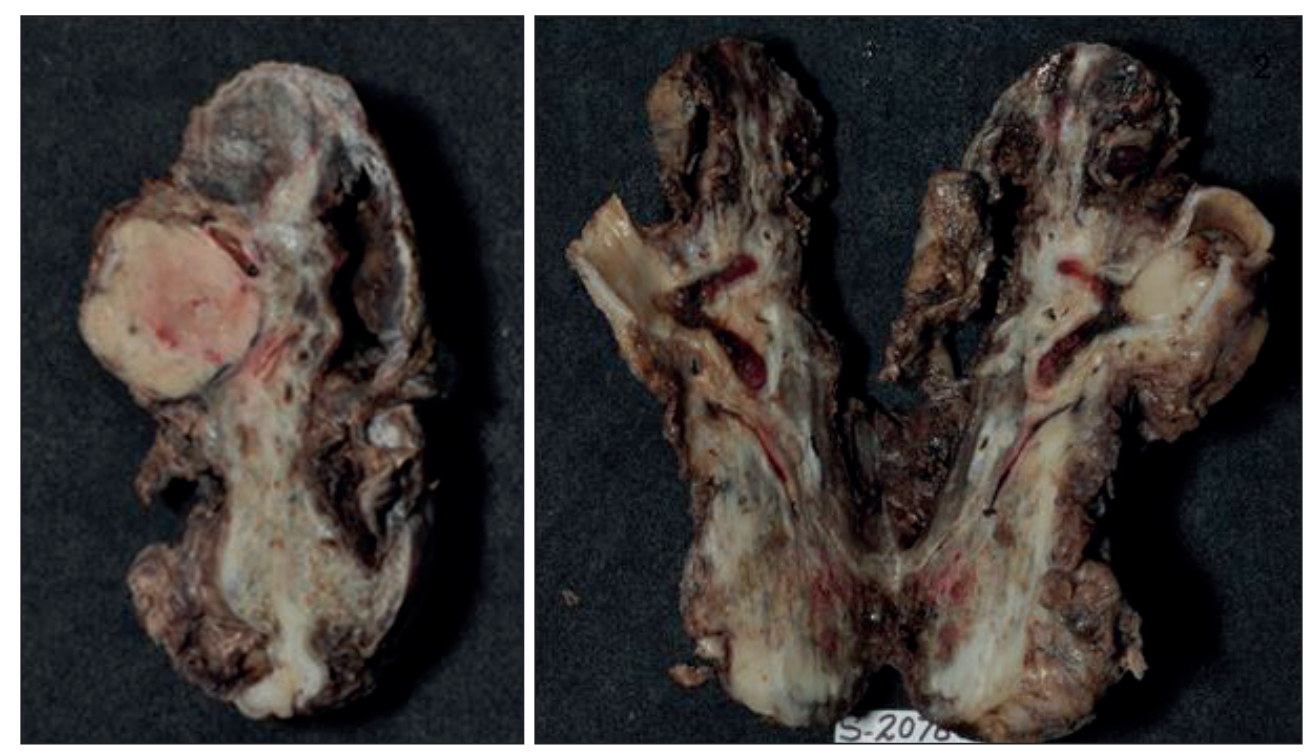

Figure 5: Gross photographs of endobronchial carcinoid tumour; a well circumscribed grayish yellow tumour. 
Table III shows average Ki67 values across different studies; however, the results vary (11-14).

The mean values of Ki67 index in the present study are $2.6 \%, 19 \%, 42.5 \%$ in TC, AC and LCNEC respectively and the cutoff values by ROC curve analysis are $7.5 \%$ for TC/AC and 32.5\% for AC/LCNEC. Of the 35 cases of TC, 3 cases have Ki67 > 7.5\% (10\%). The discrepancy in Ki67 index and mitotic count could also arise from the fact that the mitotic phase represents the smallest portion of the cell cycle and Ki-67 which detects cells from mid-G1 through S and G2 phases will detect proliferating cells that do not show mitotic figures. The mean Ki67 proliferative index significantly increases from TC to AC and poorly differentiated NETs (15). Ki67 is thus capable of distinguishing the 3 classes in a significant manner. However, in the present study, pair wise comparison between AC and LCNEC is not significant with a $\mathrm{P}$ value of 0.051 . This was probably due to very low number of cases of each subtype.

Pelosi et al. (14) reported cases where TC and AC were over diagnosed as SCC on biopsy specimen. In such cases, the Ki67 labeling index is emerging as the most useful ancillary technique. It supports mitotic count to discriminate between low grade versus high grade tumours and also helps to distinguish these cases by immunohistochemical staining of cytological smears $(16,17)$. It may reflect the tumour grade and predicts survival (18).

These tumours have different treatment modalities and survival rates, and a definite and accurate diagnosis is therefore necessary. Though TCs are low grade malignancies, they are capable of regional lymph node metastasis in $10-15 \%$ of the cases. ACs have $50 \%$ nodal and $20 \%$ distant metastases (19). Patients with TC, AC, LCNEC have a survival of $87 \%, 60 \%$ and $15-57 \%$ respectively (20-22). Surgery is the mainstay of the treatment of carcinoids. A study by Ducrocq et al. (23) showed that TCs have equivalent survival rate for limited resection versus lobectomy/pneumonectomy. A mediastinal lymph node dissection is recommended in clinical N0 central AC. Patients of AC with a consequent higher rate of nodal involvement and an adequate pulmonary reserve should receive lobectomy (24). Some reports showed that patients with ACs and regional lymph node metastasis have a high likelihood of developing recurrent disease, and if treated with surgical resection alone have a significantly worse outcome. Thus adjuvant treatment, chemotherapy or radiotherapy should be considered in such cases (25). Most LCNEC are poor candidates for surgical resection (14).
Table III: Comparison of average Ki67 values by different authors

\begin{tabular}{llll}
\hline \multicolumn{4}{c}{ Average values of Ki67 (\%) by different authors } \\
\hline & TC & AC & LNEC \\
\hline Igarashi et al, 2004 (11) & 1.3 & 8.6 & 52.2 \\
\hline Zheng et al, 2013 (12) & 3 & 7 & 60 \\
\hline Skov et al, 2010 (13) & 1.8 & 4 & 25.5 \\
\hline Pelosi et al, 2005 (14) & 2.3 & 9 & 47.5 \\
\hline Present study & 2.6 & 19 & 42.5 \\
\hline
\end{tabular}

To have accurate treatment modalities for these cases, accurate and early diagnosis is very important. Ki67 can act as an important supportive tool along with morphological features in classifying these tumours. However, extensive studies with larger case series to establish the appropriate cutoff values and follow up studies to establish its correlation with nodal and distant metastasis and overall survival are required in order to assess its validity.

In conclusion, morphological features are the gold standard for subtyping of neuroendocrine tumours. Ki-67 is a potentially meaningful marker for sub-categorization of lung NE tumours, especially in small biopsies. The mean values of Ki67 index in the present study were 2.6\%, $19 \%, 42.5 \%$ in TC, AC and LCNEC respectively and the cutoff values for differentiating TC/AC and AC/LCNEC were $7.5 \%$ and $32.5 \%$ respectively. However, the size and infiltrative pattern of these tumours are independent of the proliferation index.

\section{CONFLICT of INTEREST}

The authors have no funding, financial relationships, or conflicts of interest to disclose.

\section{REFERENCES}

1. Powell JM. Metastatic carcinoid of bone. Report of two cases and review of the literature. Clin Orthop Relat Res. 1988;230:266-72.

2. Travis W, Brambilla E, Burke A, et al. WHO Classification of Tumours of the Lung, Pleura, Thymus and Heart. $4^{\text {th }}$ ed. World Health Organization Classification of Tumours. Lyon: IARC Press, 2015.

3. Fisseler-Eckhoff A, Demes M. Neuroendocrine tumors of the lung. Cancer. 2012; 4: 777-98.

4. Travis WD, Brambilla E, Nicholson AG, Yatabe Y, Austin JHM, Beasley MB, Chirieac LR, Dacic S, Duhig E, Flieder DB10, Geisinger K, Hirsch FR, Ishikawa Y, Kerr KM, Noguchi M, Pelosi G, Powell CA, Tsao MS, Wistuba I; WHO Panel. The 2015 World Health Organization Classification of Lung Tumors: Impact of genetic, clinical and radiologic advances since the 2004 classification. J Thorac Oncol. 2015;10:1243-60. 
5. Aslan DL, Gulbahce HE, Pambuccian SE, Manivel JC, Jessurun J. Ki-67 immunoreactivity in the differential diagnosis of pulmonary neuroendocrine neoplasms in specimens with extensive crush artifact. Am J Clin Pathol. 2005; 123:874-8.

6. Klimstra DS, Modlin IR, Coppola D, Lloyd RV, Suster S. The pathologic classification of neuroendocrine tumors; a review of nomenclature, grading, and staging systems. Pancreas. 2010;39: 707-12.

7. Bosman FT, Organization WH, Cancer I. A. F. R. O. WHO Classification of Tumours of the Digestive System. 4th ed. Lyon: IARC Press, 2010.

8. Scarpa A, Mantovani W, Capelli P, Beghelli S, Boninsegna L, Bettini R, Panzuto F, Pederzoli P, delle Fave G, Falconi M. Pancreatic endocrine tumors: Improved TNM staging and histopathological grading permit a clinically efficient prognostic stratification of patients. Mod Pathol. 2010;23:824-33.

9. Pelosi G, Rindi G, Travis WD, Papotti M. Ki-67 antigen in lung neuroendocrine tumors: Unraveling a role in clinical practice. J Thorac Oncol. 2014;9:273-84.

10. Fabbri A, Cossa M, Sonzogni A, Papotti M, Righi L, Gatti G, Maisonneuve P, Valeri B, Pastorino U, Pelosi G. Ki-67 labeling index of neuroendocrine tumors of the lung has a high level of correspondence between biopsy samples and surgical specimens when strict counting guidelines are applied. Virchows Arch. 2017;470:153-64

11. Igarashi T, Jiang SX, Kameya T, Asamura H, Sato Y, Nagai K, Okayasu I. Divergent cyclin B1 expression and Rb/p16/cyclin D1 pathway aberrations among pulmonary neuroendocrine tumors. Mod Pathol. 2004;17:1259-67

12. Zheng G, Ettinger DS, Maleki Z. Utility of the quantitative Ki-67 proliferation index and CD56 together in the cytologic diagnosis of small cell lung carcinoma and other lung neuroendocrine tumors. Acta Cytol. 2013;57:281-90.

13. Skov BG, Holm B, Erreboe A, Skov T, Mellemgaard A. ERCC1 and Ki67 in small cell lung carcinoma and other neuroendocrine tumors of the lung: Distribution and impact on survival. J Thorac Oncol. 2010;5:453-9.

14. Pelosi G, Rodriguez J, Viale G, Rosai J. Typical and atypical pulmonary carcinoid tumor over-diagnosed as small-cell carcinoma on biopsy specimens: A major pitfall in the management of lung cancer patients. Am J Surg Pathol. 2005;29:179-87.
15. Reghi L, Volante M, Tavaglione V, Billè A, Daniele L, Angusti T, Inzani F, Pelosi G, Rindi G, Papotti M. Somatostatin receptor tissue distribution in lung neuroendocrine tumours: A clinicopathologic and immunohistochemical study if 218 clinically aggressive cases. Ann Oncol. 2010; 21: 548-55.

16. Lowe K, Khithani A, Lui E, Winston T, Christian D, Saad J, Jeyarajah DR. Ki-67 labeling: A more sensitive indicator of malignant phenotype than mitotic count or tumor size? J Surg Oncol. 2012;106:724-7.

17. Lin O, Olgac S, Green I, Zakowski MF, Klimstra DS. Immunohistochemical staining of cytologic smears with MIB1 helps distinguish low-grade from high-grade neuroendocrine neoplasms. Am J Clin Pathol. 2003;120:209-16.

18. Erler BS, Presby MM, Finch M, Hodges A, Horowitz K, Topilow AA, Matulewicz T. CD117, Ki-67, and p53 predict survival in neuroendocrine carcinomas, but not within the subgroup of small cell lung carcinoma. Tumour Biol. 2011;32:107-11.

19. Fink G, Krelbaum T, Yellin A, Bendayan D, Saute M, Glazer M, Kramer MR. Pulmonary carcinoid: Presentation, diagnosis, and outcome in 142 cases in Israel and review of 640 cases from the literature. Chest. 2001;119:1647-51.

20. Travis WD, Rush W, Flieder DB, Falk R, Fleming MV, Gal AA, Koss MN. Survival analysis of 200 pulmonary neuroendocrine tumors with clarification of criteria for atypical carcinoid and its separation from typical carcinoid. Am J Surg Pathol. 1998; 22:934-44.

21. Beasley MB, Thunnissen FB, Brambilla E, Hasleton P, Steele R, Hammar SP, Colby TV, Sheppard M, Shimosato Y, Koss MN, Falk R, Travis WD. Pulmonary atypical carcinoid: Predictors of survival in 106 cases. Hum Pathol. 2000;31:1255- 65.

22. Iyoda A, Hiroshima K, Nakatani Y, Fujisawa T. Pulmonary large cell neuroendocrine carcinoma: Its place in the spectrum of pulmonary carcinoma. Ann Thorac Surg. 2007;84:702-7.

23. Ducrocq X, Thomas P, Massard G, Barsotti P, Giudicelli R, Fuentes P, Wihlm JM. Operative risk and prognostic factors of typical bronchial carcinoid tumors. Ann Thorac Surg. 1998;65:1410-4.

24. Stamatis G, Freitag L, Greschuchna D. Limited and radical resection for tracheal and bronchopulmonary carcinoid tumour; Report on 227 cases. Eur J Cardiothorac Surg.1990;4:527-32.

25. Mackley HB, Videtic GM. Primary carcinoid tumors of the lung: A role for radiotherapy. Oncology. 2006;20:1537-43. 